YURI, J.E.; SOUZA, R.J.; RESENDE, G.M.; MOTA, J.H. Comportamento de cultivares de alface americana em Santo Antônio do Amparo. Horticultura Brasileira, Brasília, v.23, n.4, p.870-874, out-dez 2005.

\title{
Comportamento de cultivares de alface americana em Santo Antônio do Amparo
}

Jony E. Yuri'; Rovilson José de Souza²; Geraldo M. de Resende ${ }^{3}$; José H. Mota ${ }^{4}$

${ }^{1}$ REFRICON, Rod. Regis Bittencourt s/n km 294, 06850-000 Itapecerica da Serra-SP; E-mail: jonyyuri@uol.com.br; ${ }^{2}$ UFLA, C. Postal 37, 37200-000 Lavras-MG; ${ }^{3}$ Embrapa Semi-Árido, C. Postal 23, 56300-970 Petrolina-PE; ${ }^{4}$ UFMS, C. Postal 533, $79.804-970$ Dourados-MS

\section{RESUMO}

Com o objetivo de avaliar o comportamento de cultivares de alface do tipo americana em duas épocas de cultivo, foram conduzidos dois experimentos em Santo Antônio do Amparo (MG), de setembro a dezembro de 1998 e fevereiro a maio de 1999 em condições de túnel. Utilizou-se o delineamento de blocos ao acaso com seis cultivares (Cassino; Legacy; Lucy Brown; Lorca; Lady e Raider) e quatro repetições. As avaliações de massa fresca total e comercial, circunferência e comprimento do caule da cabeça comercial foram realizadas quando as plantas apresentaram cabeça bem formada e compacta. Na primeira época de plantio, sobressaíram-se na característica massa fresca total as cultivares Lady $\left(820,4 \mathrm{~g}_{\text {planta }}{ }^{-1}\right)$ e Lucy Brown (790,7 g planta $^{-1}$ ) sem, contudo, diferirem da cultivar Lorca $\left(626,6\right.$ g planta $\left.^{-1}\right)$. Para massa fresca comercial destacaram-se as cultivares Lady $\left(620,0 \mathrm{~g}_{\text {planta }}{ }^{-1}\right)$ e Lucy Brown (559,3 $\left.\mathrm{g} \mathrm{planta}^{-1}\right)$ com maiores rendimentos. A circunferência da cabeça comercial variou de 36,3 a $47,2 \mathrm{~cm}$ e o comprimento do caule de 3,3 a $4,5 \mathrm{~cm}$. Para a segunda época de cultivo não observou-se diferenças significativas entre as cultivares para massa fresca total e comercial. No entanto, todas as cultivares apresentaram massa fresca comercial acima de $850 \mathrm{~g} \mathrm{planta}^{-1}$. A circunferência da cabeça variou de 45,4 a $53,4 \mathrm{~cm}$ e o comprimento de caule de 3,7 a $4,9 \mathrm{~cm}$. Maiores rendimentos em termos de massa fresca foram obtidos na segunda época de plantio.

Palavras-chave: Lactuca sativa L., rendimento, competição de cultivares.

\section{ABSTRACT}

Evaluation of crisphead lettuce cultivars in Santo Antônio do Amparo, Brazil

The behavior of crisphead lettuce cultivars at two planting periods was evaluated in two experiments carried in Santo Antônio do Amparo, Minas Gerais State, Brazil, from September to December 1998 and February to May 1999, under a plastic tunnel conditions. The experimental design was a randomized complete block with six treatments (cv Cassino; Legacy; Lucy Brown; Lorca; Lady and Raider) with four replications. The evaluations of total and marketable fresh weight, circumference and stem length of the marketable head were carried out when the plants had well formed and compact heads. In the first cultivation period, the cultivars Lady $\left(820,4 \mathrm{~g} \mathrm{plant}^{-1}\right)$ and Lucy Brown (790,7 $\mathrm{g} \mathrm{plant}^{-1}$ ) presented higher fresh weight. However, they did not differ from cultivar Lorca $\left(626,6 \mathrm{~g} \mathrm{plant}^{-1}\right)$. The cultivars Lady (620.0 g plant $\left.^{-1}\right)$ and Lucy Brown (559.3 g plant $\left.^{-1}\right)$ presented the highest yield of marketable fresh weight. The circumference of marketable heads varied from 36.3 to $47.2 \mathrm{~cm}$ and the stem length from 3.3 to $4.5 \mathrm{~cm}$. No significant differences were observed among cultivars for total and commercial fresh mass in the second planting time; However, all cultivars presented commercial fresh mass above 850 g plant 1 . The marketable head circumference varied from 45.4 to $53.4 \mathrm{~cm}$ and the stem length from 3.7 to $4.9 \mathrm{~cm}$. Highest yield of fresh mass was obtained in the second planting time.

Keywords: Lactuca sativa L., yield, cultivar competition.

(Recebido para publicação em 20 de fevereiro de 2004 e aceito em 13 de junho de 2005)

A alface (Lactuca sativa L.) é uma espécie mundialmente conhecida e considerada a mais importante hortaliça folhosa (FERNANDES; MARTINS, 1999). A alface do tipo americana, denominada 'Crisphead lettuce' nos Estados Unidos, é considerada a mais importante dentre os vegetais para ser consumido em forma de saladas cruas, tendo um consumo per capita superior a $11,3 \mathrm{~kg} \mathrm{ano}^{-1}$ no Brasil (SANDERS, 1999).

O grupo da alface americana tem apresentado aumento crescente, na região do sul de Minas Gerais, devido às condições edafoclimáticas favoráveis e também devido à proximidade dos grandes centros consumidores (redes "fast food"). A região possui mais de 30 produtores em diversos municípios do sul de Minas Gerais, cultivando cerca de 1800 ha por ano, com uma produção de 10.500 toneladas desta folhosa (YURI, 2000).

De acordo com Thompson (1944), a alface é uma das hortaliças mais sensíveis às altas temperaturas e isto, na maioria das vezes, é o fator mais limitante para o não imbricamento das folhas (formação da cabeça). Com base nos resultados de Lenano (1973), Brunini et al., (1976) e Cásseres (1980), verifica-se que a alface se desenvolve bem em temperaturas entre 15 e $20^{\circ} \mathrm{C}$.

Temperaturas acima de $20^{\circ} \mathrm{C}$ estimulam e aceleram o pendoamento. Com o aumento da temperatura, a planta emite o pendão floral precocemente, interrompendo a fase vegetativa, tornando o produto impróprio para consumo e comercialização, devido à ocorrência de sabor amargo das folhas, em função do acúmulo de látex (CÁSSERES, 1980).

Jackson et al. (1999) relatam que a alface americana requer, como temperatura ideal para o desenvolvimento, $23^{\circ} \mathrm{C}$ durante o dia e $7^{\circ} \mathrm{C}$ à noite. Temperaturas muito elevadas podem provo- 
car queima das bordas das folhas externas, formar cabeças pouco compactas e também contribuir para a ocorrência de deficiência de cálcio, conhecido como "tip-burn".

Outro fator que afeta a planta é o fotoperíodo, pois a alface exige dias curtos durante a fase vegetativa e dias longos para que ocorra o pendoamento. Para Robinson et al. (1983), o pendoamento em alface é uma característica importante que influencia diretamente o desenvolvimento da cabeça. Dias longos associados a temperaturas elevadas aceleram o processo, o qual é também dependente da cultivar (NAGAI; LISBÃO, 1980; RYDER, 1986; VIGGIANO, 1990).

Segundo Conti (1994), o comprimento do dia não é problema para o cultivo da alface no verão brasileiro, pois as cultivares européias importadas já estão adaptadas a dias mais longos do que os que ocorrem no país de origem. Observa-se que a expansão da cultura está ocorrendo para as áreas de latitudes menores e, consequientemente, o fotoperíodo não é obstáculo. Entretanto, em condições de menores latitudes, verifica-se o aumento da temperatura no período do verão, havendo necessidade de se escolher áreas de elevadas altitudes.

A altitude do local é um fator que deve ser levado em consideração para o cultivo da alface, pois influencia diretamente na temperatura. Portanto, regiões de menores altitudes não são adequadas ao plantio de verão, devido ao excesso de calor. Verifica-se que nas regiões serranas do Rio de Janeiro e no cinturão verde de São Paulo, em altitudes superiores a $800 \mathrm{~m}$ é possível cultivar-se ao longo do ano. Já em localidades com altitude inferior a $400 \mathrm{~m}$, de clima quente, desde que se utilize cultivares adaptadas pode-se cultivar a alface na maioria dos meses (FILGUEIRA, 2000).

As cultivares americanas têm elevada produção de massa fresca, o que é relatado por Bernardi e Igue (1973) nas cultivares Great Lakes e New York que pesaram, em média, 644,0 e 610,0 gramas, respectivamente. Leal et al. (1974) avaliando o comportamento de cultivares de alface de diferentes grupos na região Serrana do Estado do Rio de Janeiro, numa época quente, verificaram que a cultivar Mesa 659 foi a que apresentou melhor formação de cabeça em relação às demais cultivares estudadas, com 58\% das plantas apresentando massa superior a 400,0 gramas.

Bueno (1998), nas condições de Lavras, a uma altitude de 918 metros, apresentou em junho, para a cultivar Lorca, uma massa fresca total e comercial por planta de 801,2 e 461,2 gramas, respectivamente. Utilizando a mesma cultivar, local e época de plantio, Mota (1999) obteve massa fresca total e comercial por planta de 1000 e 695 gramas, respectivamente. Em experimento realizado em Santo Antônio do Amparo (MG), a uma altitute de 1.050 metros, Alvarenga (1999) obteve massa fresca total e comercial por planta de $1011,0 \mathrm{e}$ 677,8 gramas, respectivamente, para a cultivar Raider, avaliadas nos meses de maio e junho.

Yuri (2000), em experimento realizado no município de Boa Esperança (MG), obteve para os genótipos Lucy Brown, PSR 5338, PSR 4303, PSR 0110, Empire 2000 e Seeker, produtividade comercial de 266,6; 276,1; 293,8; 301,6 ; 304,4 e 333,8 g planta ${ }^{-1}$, respectivamente, porém, não mostraram diferenças significativas comparadas à 'Raider' (333,8 g planta-1).

O presente trabalho teve como objetivo avaliar o comportamento de cultivares de alface americana em duas épocas de plantio, nas condições do município de Santo Antônio do Amparo.

\section{MATERIAL E MÉTODOS}

Foram conduzidos dois experimentos na Estação Experimental da Refricon Mercantil Ltda., no município de Santo Antônio do Amparo (MG), situado a uma altitude de 1.050 metros, em solo classificado como Latossolo Vermelho Distroférrico.

Utilizou-se o delineamento experimental de blocos casualizados, com quatro repetições, sendo os tratamentos constituídos por seis cultivares de alface americana (Cassino, Legacy, Lucy Brown, Lorca, Lady e Raider). A semeadura foi realizada em bandejas de poliestireno expandido contendo 200 células, utilizando-se o substrato comercial Plantmax HT sendo utilizadas mu- das com 30 dias de idade. O primeiro experimento foi realizado de setembro a dezembro de 1998 ( $1^{a}$ época), com transplante em $26 / 10 / 1998$, e o segundo de fevereiro a maio de 1999 (2a época), com transplante em 19/03/1999.

Com base nos resultados da análise das amostras de solo, a área experimental utilizada na primeira época foi corrigida com calcário dolomítico seis meses antes do plantio da alface. A adubação de plantio foi feita dois dias antes do transplantio, utilizando-se uma mistura de adubo formulado 4-30-16 com o termofosfato magnesiano Yoorim Master, em que se aplicou $37,5 \mathrm{~kg} \mathrm{ha}^{-1}$ de $\mathrm{N} ; 600,0 \mathrm{~kg} \mathrm{ha}^{-1}$ de $\mathrm{P}_{2} \mathrm{O}_{5}$ e $150,0 \mathrm{~kg} \mathrm{ha}^{-1}$ de $\mathrm{K}_{2} 0$. Na segunda época foi aplicado $400,0 \mathrm{~kg} \mathrm{ha}^{-1}$ de $\mathrm{P}_{2} \mathrm{O}_{5}$ e as mesmas doses de $\mathrm{N}_{\text {e }} \mathrm{K}_{2} 0$ utilizados anteriormente baseados nos dados de Raij et al. (1996).

Os canteiros foram construídos com 45,0 m de comprimento e 1,2 m de largura. A cada dois canteiros foi instalada uma estrutura de proteção, constituída de túnel alto, com 3,0 m de largura e 1,7 $\mathrm{m}$ de altura, coberto com filme plástico transparente de baixa densidade, aditivado com anti-UV, de 75 micras de espessura. O túnel teve a função de proteger as plantas do excesso de chuva (efeito guarda chuva), sendo que o mesmo ficava semi-aberto durante a condução do experimento. $\mathrm{Na}$ área central de cada canteiro foram demarcadas três parcelas, ou seja, seis em cada estrutura de túnel alto, onde os tratamentos foram distribuídos de modo aleatório. Cada parcela mediu 4,0 m de comprimento por 1,2 m de largura, onde foram plantadas quatro linhas de alface espaçadas entre si de 0,35 m. Em cada parcela, constaram 44 plantas. A área útil da parcela foi formada por 20 plantas das duas linhas centrais do canteiro.

O sistema de irrigação utilizado durante a primeira semana nas duas épocas foi por aspersão convencional e posteriormente por gotejamento. Este consistiu de duas linhas de tubo gotejador "Streamline 6000", com vazão de 1,2 L $\mathrm{h}^{-1}$ por emissor. Após a instalação dos tubos gotejadores, os canteiros foram cobertos por um filme plástico preto (mulching), com a finalidade de evitar a infestação de plantas daninhas e o contato das folhas da alface com o solo. 
Tabela 1. Massa fresca total e comercial de cultivares de alface americana em função das épocas de plantio. Santo Antônio do Amparo (MG), UFLA, 1998/1999¹.

\begin{tabular}{|c|c|c|c|c|c|}
\hline \multirow{2}{*}{ Cultivar } & \multicolumn{2}{|c|}{ Massa fresca total (g planta ${ }^{-1}$ ) } & \multicolumn{3}{|c|}{ Massa fresca comercial (g planta-1) } \\
\hline & $1^{\text {a epoca* }}$ & $2^{\mathrm{a}}$ epoca** & $1^{a}$ epoca & $2^{a}$ epo & \\
\hline Cassino & 485,6 & 1226,2 a $A$ & $332,8 \quad b \quad$ B & 858,2 & a $A$ \\
\hline Legacy & 505,4 & 1235,6 a $A$ & 376,9 b $\quad B$ & 929,1 & a $A$ \\
\hline Lucy Brown & $790,7 \mathrm{ab}$ & 1278,8 a $A$ & 559,3 a $\quad B$ & 1037,2 & a $A$ \\
\hline Lorca & 626,6 bc $\mathrm{B}$ & 1199,7 a $A$ & 406,0 b B & 926,3 & a $A$ \\
\hline Lady & $820,4 a$ & 1210,0 a $A$ & 620,0 a $\quad B$ & 970,0 & a $A$ \\
\hline Raider & $609,4 \quad c \quad B$ & 1248,5 a $A$ & 415,0 b $\quad B$ & 996,3 & a $A$ \\
\hline$\overline{C . V .}(\%)$ & 8,5 & 10,1 & 9,7 & 11,3 & \\
\hline
\end{tabular}

${ }^{1}$ Médias seguidas por letras minúsculas iguais nas colunas e maiúsculas nas linhas para cada característica não diferem entre si a 5\% de probabilidade pelo teste de Tukey; *Período de setembro a dezembro; **período de fevereiro a maio.

Uma semana após o transplantio, teve início a adubação de cobertura realizada por fertirrigação, utilizando-se os adubos solúveis nitrato de potássio, nitrato de cálcio, sulfato de magnésio e cloreto de potássio, na dose de $40,0 \mathrm{~kg}$ $\mathrm{ha}^{-1}$ de $\mathrm{N}, 80,0 \mathrm{~kg} \mathrm{ha}^{-1}$ de $\mathrm{K}_{2} 0$ e $50,0 \mathrm{~kg}$ $\mathrm{ha}^{-1}$ de $\mathrm{Ca}$, aplicados diariamente . A fertirrigação foi feita até dois dias antes da colheita.

O controle de doenças e pragas na primeira época foi realizado com pulverizações semanais com produtos à base de cobre e com inseticida piretróide. Na segunda época, as pulverizações foram realizadas, com os mesmos produtos a cada 15 dias, pois as condições climáticas foram menos favoráveis às pragas e doenças, devido à menor precipitação. Para o controle das plantas daninhas, utilizou-se, a capina manual em torno das covas e o herbicida de contato paraquat entre os canteiros, utilizando protetor para evitar a deriva (Chapéu de Napoleão).

As colheitas foram realizadas aos 67 e 78 dias para os plantios nos anos de 1998 e 1999, respectivamente, quando as plantas apresentaram cabeça bem formada e compacta, sendo avaliadas a massa fresca total e comercial, circunferência da cabeça comercial e comprimento do caule. Para a obtenção da massa fresca total a planta foi cortada rente ao solo, com as folhas externas e internas e com a cabeça compacta. A massa fresca comercial foi obtida removendo-se as folhas externas.

Os dados obtidos foram submetidos à análise de variância conjunta, sendo as médias comparadas pelo teste de Tukey ao nível de 5\% de probabilidade.

\section{RESULTADOS E DISCUSSÃO}

Os resultados evidenciaram efeitos significativos para cultivares, épocas de plantio e a interação entre estes fatores (Tabelas 1 e 2). Para a primeira época de plantio, maiores rendimentos de massa fresca total foram obtidos com as cultivares Lady (820,4 g planta $\left.^{-1}\right)$ e Lucy Brown (790,7 g planta $\left.^{-1}\right)$ que não mostraram diferenças significativas entre si (Tabela 1). Mota et al. (2003) em condições de verão em Lavras; sob cultivo em túnel alto, obtiveram massa fresca de 650,0 g planta $^{-1}$, para a cultivar Raider, assim como Yuri et al. (2002), nas mesmas condições, no município de Boa Esperança, obtiveram para a cultivar Lucy Brown, 972,0 g planta ${ }^{-1}$, resultados estes semelhantes aos obtidos no experimento. No entanto, sob condições de casa de vegetação, Salatiel et al. (2001) utilizando a cultivar Lorca, nas condições de Jaboticabal, no verão e outono obtiveram 308,5 $\mathrm{g}_{\text {planta }}{ }^{-1}$, resultado bem inferior ao obtidos no presente experimento.

Na segunda época de cultivo, as cultivares não apresentaram diferenças significativas entre si para massa fresca total que oscilou entre $1119,7 \mathrm{~g}$ planta $^{-1}$ (cultivar Lorca) a 1278,8 g planta $^{-1}$ (cultivar Lucy Brown). Nas mesmas condições de cultivo, no município de Santana da Vargem, Yuri et al. (2004), obtiveram massa fresca total de 1075,2 g plan$\mathrm{ta}^{-1}$ para a cultivar Raider.

As cultivares Lady e Lucy Brown apresentaram massa fresca total de 620,0 e 559,3 g planta $^{-1}$, respectivamen- te, com os melhores desempenhos na primeira época de plantio (Tabela 1). Em condições de verão, Mota et al. (2003) em sistema de cultivo de túnel alto, em Santana da Vargem, encontraram variações para as cultivares Raider e Lucy Brown entre 333,8 a 266,6 g planta $^{-1}$, valores bem inferiores aos obtidos por estas cultivares no presente experimento $\left(415,0\right.$ e $559,3 \mathrm{~g}$ planta $^{-1}$, respectivamente).

Para a segunda época de cultivo não se verificaram diferenças significativas entre as cultivares, com massa fresca comercial entre 858,2 e 1037,2 g plan$\mathrm{ta}^{-1}$. Estes resultados são superiores aos observados por Mota (1999) e Bueno (1998) em condições de cultivo semelhante em Lavras, utilizando a cultivar Lorca, assim como aos alcançados por Gadum et al. (2002) em Botucatu, para as cultivares Raider e Lucy Brown. Todavia, Yuri et al. (2002) obtiveram resultados similares com a cultivar Raider em Boa Esperança (972,0 g planta $\left.{ }^{-1}\right)$.

A cultivar Lady apresentou uma circunferência de cabeça de $47,2 \mathrm{~cm}$ na primeira época e de 52,0 cm na segunda. É uma cultivar que apresenta como destaque o tamanho da cabeça comercial, o qual determina o melhor rendimento industrial. Na primeira época, as cultivares Lady, Lucy Brown e Lorca apresentaram os melhores desempenhos com 47,2; 45,9 e 43,0 cm, respectivamente, de circunferência de cabeça, sem, no entanto diferirem entre si. As cultivares Legacy, com 36,3 cm e Cassino, com $40,6 \mathrm{~cm}$, foram as que apresentaram os menores tamanhos de cabeça (Tabela 2). Resultados semelhantes foram observados por Mota et al. (2003) que em condições de verão encontraram variações entre 34,7 a 41,5 cm.

Na segunda época de plantio, a cultivar Lucy Brown apresentou a maior circunferência com $53,4 \mathrm{~cm}$, não diferindo das cultivares Lady $(52,0 \mathrm{~cm})$, Lorca $(51,6 \mathrm{~cm})$ e Raider $(49,1 \mathrm{~cm})(\mathrm{Ta}-$ bela 2). Estes resultados foram superiores aos obtidos por Bueno (1998) onde a cultivar Lorca apresentou uma circunferência da cabeça de $45,0 \mathrm{~cm}$, e por Mota (1999) que verificou uma circunferência de $46,5 \mathrm{~cm}$ na mesma cultivar.

Na Tabela 2 observa-se diferença significativa no comprimento de caule 
entre as cultivares. No entanto, essa diferença, não afetou a formação da cabeça comercial. Na primeira época de plantio, a cultivar Legacy apresentou o menor comprimento com $3,3 \mathrm{~cm}$; no entanto, estatisticamente sem diferenciar das cultivares Cassino, Lucy Brown, Lady e Raider. O maior valor foi apresentado pela cultivar Lorca com $4,5 \mathrm{~cm}$ (Tabela 2). Resultados semelhantes foram observados para a segunda época, onde a cultivar Lady mostrou o menor comprimento $(3,7 \mathrm{~cm})$, seguida pelas cultivares Cassino, Raider e Lucy Brown, sem diferirem estatisticamente. O comprimento foi inferior ao apresentado por Bueno (1998), com a cultivar Lorca, de 6,8 cm. Mota et al. (2003) em cultivo de alface sob túnel alto, verificaram para as cultivares Raider e Lucy Brown comprimentos de caule de 7,1 e $5,3 \mathrm{~cm}$, respectivamente. Menores comprimentos de caule são desejáveis para a alface do tipo americana, principalmente quando destinada à indústria de beneficiamento, uma vez que proporcionam menores perdas durante o processamento. Por outro lado, o caule excessivamente comprido acarreta uma menor compacidade da cabeça e dificulta o beneficiamento, afetando a qualidade final do produto (YURI et al., 2002; RESENDE et al., 2003).

Nas duas épocas avaliadas observaram-se diferenças significativas na massa fresca total e comercial para todas as cultivares testadas, sendo a segunda época a mais produtiva. Assim como para circunferência da cabeça comercial, com exceção para a cultivar Lady. No comprimento do caule somente as cultivares Legacy e Raider apresentaram os menores valores na primeira época de cultivo. Entretanto, para as duas épocas, todos os materiais apresentaram o comprimento de caule reduzido e dentro de um patamar considerado aceitável de acordo com Resende (2004) que relata caules até $6,0 \mathrm{~cm}$ como os mais adequados, sendo aceitáveis até o patamar de 9,0 cm e inaceitáveis ou menos recomendados para processamento aqueles acima deste valor.

A melhor performance do cultivo observada na segunda época de plantio pode ser explicada pela melhor adaptação da cultura às condições de temperaturas mais amenas, tendo como ótima a

Tabela 2. Circunferência de cabeça e comprimento de caule de cultivares de alface americana em função das épocas de plantio. Santo Antônio do Amparo (MG), UFLA, 1998/1999.

\begin{tabular}{|c|c|c|c|c|}
\hline \multirow{3}{*}{$\frac{\text { Cultivar }}{\text { Cassino }}$} & \multicolumn{2}{|c|}{ Circunferência da cabeça $(\mathrm{cm})$} & \multicolumn{2}{|c|}{ Comprimento do caule (cm) } \\
\hline & $1^{\mathrm{a}}$ epoca* & $2^{a}$ epoca** & $1^{\mathrm{a}}$ epoca & $2^{\mathrm{a}}$ epoca \\
\hline & 40,6 cd $B$ & $45,4 \quad c \quad A$ & $4,1 a b \quad A$ & $4,1 \mathrm{ab} A$ \\
\hline Legacy & 36,3 & 47,3 bc $A$ & 3,3 b $B$ & 4,9 a $\quad A$ \\
\hline Lucy Brown & $45,9 \mathrm{ab} \quad \mathrm{B}$ & $53,4 \mathrm{a}$ & $4,2 a b \quad A$ & $4,8 \mathrm{ab} \quad \mathrm{A}$ \\
\hline Lorca & 43,0 abc B & $51,6 \mathrm{ab} \quad \mathrm{A}$ & 4,5 a $\mathrm{A}$ & 4,9 a $\quad A$ \\
\hline Lady & $47,2 \mathrm{a}$ & $52,0 \mathrm{ab} \quad \mathrm{A}$ & 3,6 ab $A$ & 3,7 b A \\
\hline Raider & 42,4 bc $B$ & $49,1 \mathrm{abc} A$ & $3,7 \mathrm{ab} \quad \mathrm{B}$ & $4,6 \mathrm{ab} A$ \\
\hline C.V. $(\%)$ & 3,7 & 5,9 & 10,4 & 12,0 \\
\hline
\end{tabular}

Médias seguidas por letras minúsculas iguais nas colunas e maiúsculas nas linhas para cada característica não diferem entre si a 5\% de probabilidade pelo teste de Tukey; *Período de setembro a dezembro; **Período de fevereiro a maio.

faixa de 15,5 a $18,3^{\circ} \mathrm{C}$, conforme relata Sanders (1999), podendo tolerar alguns dias com temperaturas de 26,6 a $29,4^{\circ} \mathrm{C}$, desde que as temperaturas noturnas sejam baixas.

Em função dos resultados obtidos no presente estudo, pode-se concluir, para as condições do município de Santo Antônio do Amparo que a produção de alface do tipo americana é viável nas duas épocas de cultivo testadas, sendo a segunda época, a mais favorável para a obtenção de melhores rendimentos. As cultivar Lady e Lucy Brown destacaram-se como as mais recomendadas para o cultivo na primeira época, considerando a massa fresca comercial. Para a segunda época de cultivo todas as cultivares mostraram-se produtivas no que se refere à massa fresca comercial, não diferindo entre si; no entanto, levandose em consideração a maior circunferência de cabeça comercial e menor comprimento de caule, sugere-se as cultivares Lucy Brown, Lady e Raider como as mais promissoras.

\section{LITERATURA CITADA}

ALVARENGA, M.A.R. Crescimento, teor $e$ acúmulo de nutrientes em alface americana (Lactuca sativa L.) sob doses de nitrogênio aplicadas no solo e de níveis de cálcio aplicados via foliar. 1999. 117 f. (Tese doutorado) - UFLA, Lavras.

BERNARDI, J.B.; IGUE, T. Comportamento de cultivares de alface na região de Campinas. VI. Cultura de Setembro a Novembro de 1972. Revista de Olericultura: Campinas, v.13, p.29-31, 1973.

BRUNINI, O.; LISBÃO, R.S.; BERNARDINI, J.B.; FORNASIER, J.B.; PEDRO JUNIOR, M.J. Temperaturas básicas para alface, cultivar White Boston, em sistemas de unidades térmicas.
Bragantia: Campinas, v.19, n.35, p.213-219, 1976. BUENO, C.R. Efeito da adubação nitrogenada em cobertura via fertirrigação por gotejamento para a cultura da alface tipo americana em ambiente protegido. 1998. 54 f. (Tese mestrado) - UFLA, Lavras. CÁSSERES, E. Producción de hortalizas. São José: Instituto Interamericano de Ciências Agrícolas, 1980. 387 p.

CONTI, J.H. Caracterização de cultivares de alface (Lactuca sativa L.) adaptadas aos cultivos de inverno e verão. 1994. 117 f. (Tese mestrado) ESALQ, Piracicaba.

FERNANDES, H.S.; MARTINS, S.R. Cultivo de alface em solo em ambiente protegido. Informe agropecuário, Belo Horizonte, v.20, n.200/201, p.53-56, 1999.

FILGUEIRA, F.A.R. Novo Manual de olericultura: agrotecnologia moderna na produção e comercialização de hortaliças. Viçosa: UFV. 2000, 402 p.

GADUM, J.; SEABRA JÚNIOR, S.; CARNEIRO JÚNIOR A.G.; GOTO, R. Avaliação de diferentes cultivares de alface tipo Americana na região de Botucatu sob ambiente protegido. Horticultura Brasileira, Brasília, v.20, n.2, julho, 2002. Suplemento 2. CD-ROM.

JACKSON, L.; MAYBERRY, K.; LAEMMLEN, F.; KOIKE, S.; SCHLUBACK, K. Iceberg lettuce production in California. Disponível em: <http// www.vegetablecrops.ucdavis>. Acesso em: 24 out. 1999.

LEAL, N.R.; LIBERAL, M.T.; COELHO, R.G. Comportamento de cultivares de alface (Lactuca sativa L.) na região serrana do Estado do rio de Janeiro. Revista Ceres, Viçosa, v.21, n.118, p.506509, 1974.

LENANO, F. Como se cultivam las hortalizas do hojas. Barcelona: Editorial Vecchi, 1973. 228 p. MOTA, J.H. Efeito do cloreto de potássio via fertirrigação na produção de alface americana em cultivo protegido. 1999. 46 f. (Tese mestrado) UFLA, Lavras.

MOTA, J.H.; YURI, J.E.; FREITAS, S.A.C.; RODRIGUES JUNIOR, J.C.; RESENDE, G.M.; SOUZA, R.J. Avaliação de cultivares de alface americana durante o verão em Santana da Vargem, MG. Horticultura Brasileira, Brasília, v.21, n.2, p.234-237, 2003.

NAGAI, H.; LISBÃO, R.S. Observações sobre resistência ao calor em alface (Lactuca satival L.). Revista 
de Olericultura, Campinas, n.18, p.7-13, 1980. RAIJ, B.; CANTARELLA, H.; QUAGGIO, J.A.; FURLANI, A.M.C. (eds). Recomendações de adubação e calagem para o Estado de São Paulo. 2 ed.Campinas: IAC, 1996. p.22-27. (Boletim 100). RESENDE, G.M. Características produtivas, qualidade pós-colheita e teor de nutrientes em alface americana (Lactuca sativa $L$.) sob doses de nitrogênio e molibdênio, em cultivo de verão e de inverno. 2004. 139 f. (Tese doutorado) - UFLA, Lavras.

RESENDE, G.M.; YURI, J.E.; MOTA, J.H.; SOUZA, R.J.; FREITAS, S.A.C.; RODRIGUES JÚNIOR, J.C. Efeitos de tipos de bandejas e idade de transplantio de mudas sobre o desenvolvimento e produtividade de alface americana.
Horticultura Brasileira, Brasília, v.21, n.3, p.562567, 2003.

ROBINSON, R.W.; McCREIGT, J.D.; RYDER,

J.E. The genes of lettuce and closely related species. In: JANICK, J. (ed.) Plant breeding reviews. Westport: AVI, 1983, v.1, 397 p.

RYDER, E.J. Lettuce breeding. In: Breeding vegetables crops. Westport: AVI, 1986. p. 433-474. SALATIEL, L.T.; BRANCO, R.B.F.; MAY, A.; BARBOSA, J.C.; PAULA, C.M.; CECILIO FILHO, A.B. Avaliação de cultivares de alface em diferentes épocas de plantio, cultivadas em casa de vegetação. Horticultura Brasileira, Brasília, v.19, Suplemento CD-ROM, julho 2001.

SANDERS, D. C. Lettuce production: Disponível em: <http//www.ces.ncsu.edu/depts/hort/hil/ hil-11>. Acesso em: 11 out. 1999.

THOMPSON, H.C. Lettuce varieties and culture.
Washington: USDA, 1944. 38 p. (Farmer's Bulletin, 1953)

VIGGIANO, J. Produção de sementes de alface. In: CASTELlane, P.D. (org.) Produção de sementes de Hortaliças. Jaboticabal: FCAV/FUNEP, 1990. p.1-15.

YURI, J.E. Avaliação de cultivares de alface americana em duas épocas de plantio em dois locais do sul de Minas Gerais. 2000, 51 f. (Tese mestrado) - UFLA, Lavras.

YURI, J.E.; MOTA, J.H.; RESENDE, G.M.; SOUZA, R.J.; RODRIGUES JUNIOR, J.C. Desempenho de cultivares de alface tipo americana em cultivo de outono no sul de Minas Gerais. Ciência e Agrotecnologia, Lavras, v.28, n.2, p.284-288, 2004.

YURI, J.E.; SOUZA, R.J.; FREITAS, S.A.C.; RODRIGUES JÚNIOR, J.C.; MOTA, J.H. Comportamento de cultivares de alface tipo americana em Boa Esperança. Horticultura Brasileira, Brasília, v.20, n.2, p.229-232, jun. 2002. 